\title{
Cannabidiol Oil - Time to talk to Older Adults
}

\author{
Senthil Meenrajan ${ }^{1 *}$, Magdalena Leszko ${ }^{2}$ and Dianne Goede ${ }^{1}$ \\ ${ }^{1}$ Associate Professor, University of Florida, USA \\ ${ }^{2}$ Assistant Professor, University of Szczecin, USA
}

Submission: September 16, 2021; Published: September 27,2021

*Corresponding author: Senthil Meenrajan, Associate Professor, University of Florida, Internal Medicine, Gainesville, USA

\begin{abstract}
Cannabis use, either as medical marijuana or Cannabidiol (CBD) oil is becoming more popular and prevalent in all age groups, including older adults. CBD oil is more appropriate for some, since it does not have psychoactive properties and is proving effective in the treatment of a number of chronic medical conditions, which a number of older adults grapple with. It is important for clinicians to have open discussions with patients and caregivers on CBD oil use. It is also important to be aware of practical problems including absorption, distribution and drug-drug interactions. Lastly, being updated periodically on local laws and regulations relating to CBD oil is essential.
\end{abstract}

Keywords: Cannabidiol oil; Marijuana; Older adults; Tetrahydrocannabinol; Primary care physician

Abbreviations: CBD: Cannabidiol; THC: Tetrahydrocannabinol; PCP: primary care physician

\section{Background}

Cannabis use is becoming more prevalent throughout the world. More countries are allowing legal use of cannabis for medical and recreational purposes. Compared to previous decades, the current generation of older adults is more likely to have been exposed to cannabis and other recreational drugs during younger years, more likely to be accepting of its use and willing to pursue that as a treatment option for chronic medical illness [1]. This has profound implications for healthcare systems around the world.

When a person uses or is contemplating use of cannabis or cannabidiol oil, the two key systems they are likely to think about is the health system and legal system. The following are likely common queries for anybody:

a) how is this going to affect my health now?

b) is this a beneficial or harmful intervention for the long term?

c) are there legal consequences to possessing and using marijuana or CBD oil?

d) The older person is likely to benefit from a clear understanding of the current medical and legal standing on these substances. Many of them are unsure what it should be labelled - is it a medicine, herb, nutraceutical, drug or something else? Unfortunately, the places they commonly turn to for information- physicians and legal resources, can often come short on information. With the prevalence of CBD oil and increasing frequency of use, it behooves clinicians to be aware of the basics of these compounds and their use.

\section{Content}

Cannabis related products broadly fall under 2 categories, marijuana and hemp. These products have varying concentrations of THC and CBD. Typically, hemp has THC concentration less than $0.3 \%$ (in some countries $0.2 \%$ ) and marijuana has higher concentrations of THC. The neurological effects or the 'high' from cannabis products is related to the THC content in it. In essence, all cannabis products have the peripheral effects of cannabis but CBD based products including the oil does not give the psychotropic effect. So, is it a drug? Dictionaries define a drug as a substance that alters the physiological state of an organism or a substance that can be used to diagnose or treat diseases. In that sense both marijuana and CBD oil should be classified as drugs. Marijuana and high THC containing products is tightly regulated in almost all countries and recently incorporated for use in medical treatment. Some countries also allow recreational use. On the other hand, CBD oil based edible products are essentially available over the counter, without prescription and online as well. Depending on the country of residence, local laws allow for CBD oil to be used for any indication or only for regulated, medicinal use. In some countries CBD oil can be found in a variety of foods, drinks, cosmetics etc. The ease of availability of CBD oil and the myriad of clinical conditions for which it is purported to help, makes it an attractive treatment option for older adults with chronic medical comorbidities. 


\section{Benefit in many clinical conditions}

Older patients often have multiple medical conditions and comorbidities that are often chronic and do not have definite therapeutic end points. Many of the current therapies prescribed often have their own unique side effects and is sometimes ineffective in resolving the primary symptoms of the patient. Based on prior anecdotal personal experience, recommendation from friends, family or online resources, many of these older patients are willing to try CBD oil either topically or ingested. Prior studies have shown that CBD oil is effective in conditions like anxiety, insomnia, seizure, behavioral symptoms of dementia, chronic pain from a number of conditions including arthritis (inflammatory and degenerative), neuropathy, spastic neurological conditions [2]. In addition, people also use it for chemotherapy associated nausea and cancer related pain. Because of its anti-inflammatory effects, its purported to help in inflammatory conditions as well. The list of clinical conditions where CBD oil is beneficial will likely only grow with time.

\section{What to know in users}

In older patients who use CBD oil it is important for physicians and treating teams to know its absorption, interaction with other meds and metabolism. With age, changes in metabolism and organ function impact the pharmacokinetics and pharmacodynamics of any drug including CBD oil. Higher levels of CBD is noted when taken with fatty food or high calorie meals [3]. So, the general eating habits of the older could greatly impact the drug levels they attain. Since metabolism is dependent on cytochrome P 450 pathway, potential interactions exist with commonly used medications in elderly, like warfarin and omeprazole. Prior experience however has shown that CBD oil is generally well tolerated and the rates of reported adverse effects is generally low. Studies seem to suggest that when used for chronic pain the rates of side effects related to cannabis products is no greater than other conventional therapies [4].

\section{Physicians and patients}

Our experience has been that older patients and/or their caregivers may not always feel comfortable bringing up the conversation about CBD oil use with their primary care physician (PCP) or any treating clinician. This is true even to get information aboutCBD oil lest they come across as a 'drug seeker'. Many patients and caregivers use it and don't necessarily inform their physicians about it. Having direct conversation with patients and families about all aspects of their care is likely to enhance transparency and trust. However, when conversing with other clinicians we find that not everyone has a clear understanding to queries like, whether CBD oil is helpful for specific clinical conditions, is it harmful for the older and should we be recommending it's use at all.

\section{The law}

It is imperative that everyone understand the local laws relating to use of all cannabis related products. Many countries legally permit use of CBD oil while some restrict its use for medicinal use only. In a small number of countries, it's still banned i.e. when older patients travel to places like the middle east they cannot carry it with them. Almost all countries have restrictions on use of marijuana, with only a handful of countries allowing recreational use. In the US, almost all states allow use of CBD derived from hemp. Marijuana use is allowed for medicinal and recreational use in some states and for medicinal use only in some other [5]. This is a moving target and it is contingent upon clinicians to know the local laws and advice patients accordingly.

\section{Summary}

In summary,

a) CBD oil is proving effective in a number of chronic medical conditions and it's use is prevalent in older adults.

b) Clinicians should become comfortable discussing CBD oil use and be aware of potential problems as well.

c) Laws relating to CBD oil vary, depending on the country and region. Being updated on the local laws is imperative.

It is important that everyone be aware of the basics of CBD oil, it's uses, availability and local laws. It is imperative that clinicians treating older patients openly broach the topic of CBD oil as a treatment option for clinical conditions where it has shown benefit. It is best that there are transparent discussions and management plans, with the common goal of improving the quality of life of older- one where CBD products are likely to become an entrenched option.

\section{References}

1. Kaskie B, Ayyagari P, Milavetz G, Shane D, Arora K (2017) The Increasing Use of Cannabis Among Older Americans: A Public Health Crisis or Viable Policy Alternative? The Gerontologist 57(6): 1166-1172.

2. Beedham W, Sbai M, Allison I, Coary R, Shipway D (2020) Cannabinoids in the Older Person: A Literature Review. Geriatrics (Basel) 5(1): 2.

3. Epidiolex (cannabidiol) (2018) Package insert. Carlsbad, CA: Greenwich Biosciences Inc.

4. Abuhasira R, Ron A, Sikorin I, Novack V (2019) Medical Cannabis for Older Patients-Treatment Protocol and Initial Results. J Clin Med 8(11): 1819.

5. https://www.ncsl.org/research/health/state-medical-marijuanalaws.aspx 
This work is licensed under Creative

Commons Attribution 4.0 License

DOI: 10.19080/OAJGGM.2021.06.555684
Your next submission with Juniper Publishers will reach you the below assets

- Quality Editorial service

- Swift Peer Review

- Reprints availability

- E-prints Service

- Manuscript Podcast for convenient understanding

- Global attainment for your research

- Manuscript accessibility in different formats ( Pdf, E-pub, Full Text, Audio)

- Unceasing customer service

Track the below URL for one-step submission https://juniperpublishers.com/online-submission.php 